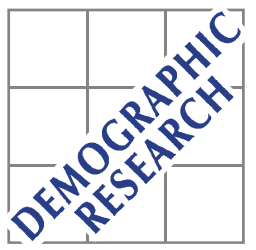

Demographic Research a free, expedited, online journal

of peer-reviewed research and commentary in the population sciences published by the Max Planck Institute for Demographic Research

Konrad-Zuse Str. 1, D-18057 Rostock · GERMANY

www.demographic-research.org

DEMOGRAPHIC RESEARCH

VOLUME 15, ARTICLE 11, PAGES 329-346

PUBLISHED 02 NOVEMBER 2006

http://www.demographic-research.org/Volumes/Vol15/11/

DOI: 10.4054/DemRes.2006.15.11

Research Materials

\title{
An evaluation of the one percent clustered sample of the 1990 census of China
}

William Lavely

William M. Mason

(C) 2006 Lavely \& Mason

This open-access work is published under the terms of the Creative Commons Attribution NonCommercial License 2.0 Germany, which permits use, reproduction \& distribution in any medium for non-commercial purposes, provided the original author(s) and source are given credit.

See http:// creativecommons.org/licenses/by-nc/2.0/de/ 


\section{Table of Contents}

1 Introduction $\quad 330$

$\begin{array}{lll}2 & \text { Clustering } & 331\end{array}$

3 Duplicates 331

$4 \quad$ Geographic coverage $\quad 332$

$5 \quad$ National comparisons of sample and census $\quad 335$

6 County-level comparisons of sample and census 340

7 Discussion 342

$8 \quad$ Acknowledgements 342

References 343

$\begin{array}{ll}\text { Appendix } 1 & 344\end{array}$ 


\title{
An evaluation of the one percent clustered sample of the 1990 census of China
}

\author{
William Lavely ${ }^{1}$ \\ William M. Mason ${ }^{2}$
}

\begin{abstract}
We describe and evaluate a one percent clustered sample of the 1990 Census of China, the largest publicly-available micro sample of any Chinese census, using direct inspection as well as comparisons with published data drawn from the complete enumeration. In the absence of official documentation, we elucidate the basis of the clustering; detect duplicate cases; report corrected totals; and make comparisons between the sample data and tabulations based on the complete enumeration at the province and county levels. Although the sample contains several anomalies, we conclude that it is broadly serviceable.
\end{abstract}

\footnotetext{
${ }^{1}$ Sociology Department and Center for Studies in Demography and Ecology; University of Washington. E-mail: lavely@u.washington.edu

${ }^{2}$ Sociology Department and California Center for Population Research, University of California-Los Angeles. E-mail: masonwm@ucla.edu
} 


\section{Introduction}

Two micro-samples of the 1990 Chinese Census have circulated in China and abroad. The first, in order of creation, is a one percent sample of rural administrative villages (xingzheng cun) and urban neighborhoods known as street committees (jiedao weiyuanhui). ${ }^{3}$ The second is a one percent sample of households. We refer to the former, the subject of this article, as the "one percent clustered sample," and to the latter as the "one percent household sample." These data sets are not public use micro samples (PUMS) in the sense understood by users of, for example, U.S. Census data. No official printed documentation has been released that is specific to either sample, and, in particular, there is no documentation or evaluation of the method and procedures used to draw the samples.

Recently the China Population Information and Research Center has made the one percent clustered sample available through the Texas A\&M China Archive. ${ }^{4}$ The one percent clustered sample is thus the only publicly-available micro sample of the 1990 census; indeed, it is largest readily available micro sample of any Chinese census. ${ }^{5} \mathrm{We}$ obtained the clustered sample and corresponding mortality data separately, from unofficial sources. Other researchers have obtained the clustered sample independently and have made use of it (e.g., Fan and Huang 1998; Li and Zhu 2000; Huang 2001). Our clustered sample is identical to the one purveyed by Texas A\&M, except that the latter does not contain mortality data.

This paper evaluates the one percent clustered sample, using direct inspection as well as a series of comparisons with published data drawn from the complete enumeration. We first discuss the nature of the clustering, and report what we know about the sampling of clusters. We then note the existence of duplicate cases, and report corrected totals when duplicates are dropped. Subsequent sections describe geographic coverage of the one percent clustered sample, compare sample to published 100 percent tabulations for basic descriptors, and report selected comparisons between sample and 100 percent enumeration data at the county level.

\footnotetext{
${ }^{3}$ An administrative village consists of one or several adjacent natural villages, and is the lowest level rural civil unit. In 1990, a neighborhood (street committee) was the corresponding urban civil unit.

${ }^{4}$ As of August 1, 2006, the data could be downloaded from The China Archive web site http://chinaarchive.tamu.edu/portal/site/chinaarchive/.

${ }^{5} \mathrm{~A} 1$ per 1,000 sample of the 1982 Chinese census is available through IPUMS International http://www.ipums.umn.edu/. No micro sample of the 2000 census has been publicly released.
} 


\section{Clustering}

Lacking any documentation on the method used in sampling, our description of the clustered sample relies on inference and a bit of hearsay. We have been told that the clustered sample was drawn as a way to provide a timely preview of census results, before final tabulations based on the complete enumeration could be prepared. We suspect, but cannot verify, that the sample is a systematic selection of all of the living persons in every hundredth administrative village (or urban neighborhood) within each province, and of all deaths in the sampled places that occurred in the 18 months leading up to the official July 1, 1990 date of the census. ${ }^{6}$ Like the 1990 Census itself (except for national totals published in selected documents, e.g., State Council Population Census Office (1993)), the clustered sample contains civilians only.

Administrative villages and urban neighborhoods lend themselves as sampling units because they also serve as census districts, and census returns are sent up the line bundled by village or neighborhood. Sampling and data entry presumably took place in provincial offices. These circumstances may explain some anomalous aspects of the sample.

\section{Duplicates}

Duplicate cases are one such anomaly. Duplicates appeared in approximately half the provinces, and in all cases entire sample villages were duplicated. We considered the possibility that the duplicates were inserted intentionally, perhaps as a weighting scheme. But because the sample is far more faithful to the 100 percent tabulations (State Council Population Census Office 1993) when the duplicates are omitted, it appears more likely that the duplicates resulted from errors in data processing. In their discussion of the one percent clustered sample $\mathrm{Li}$ and $\mathrm{Zhu}(2000: 228)$ also conclude that the duplicates are due to processing errors. We have removed the duplicates from all computations reported in this paper. Users should note that the Texas A\&M data set also contains the duplicates.

Without duplicate records the sample consists of 8,514 administrative villages or urban neighborhoods containing 11,475,104 enumerated persons, which averages to 1,348 persons per sample unit. In addition there are 99,196 records of persons who died in the 18 months prior to the census.

${ }^{6}$ According to the codebook, "this dataset (1\% sampling) was prepared taking villages as sampling unit ..." (State Statistical Bureau 1994). 


\section{Geographic coverage}

The clustered sample contains data in all 30 provinces and regions covered by the 1990 census. We consider first the extent to which the clustered sample reproduces the distribution of population across provinces and the municipalities with provincial status in 1990 (Beijing, Tianjin, and Shanghai). Table 1 shows the percentage distribution of population by province in the complete census, and the ratio of the sample to complete census percentage in each province. A ratio greater than one indicates that a province is oversampled. A ratio less than one indicates that a province is undersampled. The ratio varies from a low of .82 in Ningxia to a high of 1.29 in Tianjin Municipality, two provincial level units with small populations. Because the sample units are clusters, the sampling variability tends to be greater than would be expected for a simple random sample of individuals, and the extreme ratios occur in provinces with very small proportions of the population. The ratio in larger provinces generally varies between .95 and 1.05 .

There is also broad geographic coverage within provinces. Approximately 91 percent of China's 2,845 county-level units contain at least one sample administrative village or urban neighborhood. Among the 2,600 county-level units with coverage, there is an average of 3.2 sample units per county. Sample coverage is shown in the accompanying map of China's counties (Figure 1). Counties containing at least one village unit in the sample are shown in gray or black, while counties with no coverage are in white. Coverage is quite regular in China Proper and the northeast, as contrasted with the sparser coverage in the Inner Asian regions of Inner Mongolia, Xinjiang, and Tibet, and parts of Gansu and Qinghai provinces. As may be seen in Table 1, none of these provinces is under-sampled. The sparseness of populations in these areas appears to explain the lack of coverage. Tibet, however, is an exception.

The sample for Tibet lacks cities and towns and is thus entirely rural. According to the official 100 percent tabulations for 1990 (Tibet Autonomous Region Population Census Office 1992), the Tibet Autonomous Region is 11.5 percent urban. The Tibet sample consists of 23 villages distributed over 10 of 78 possible counties. Thirteen villages are in a single county (Dingri, the site of Mount Everest), two are in one county, and the remaining eight are distributed one per county. It is likely that the sample villages not in Dingri are composites of county sub-samples. This is suggested by the large size of these units (approximately seven times as large as the Dingri sample villages), and by their sample code numbers, each of which is "1." The Tibet sample thus appears to have been constructed according to different principles from the rest of the one percent clustered sample. Nonetheless, the sample data accord well with the 100 percent tabulations for rural Tibet (Tibet Autonomous Region Population Census 
Table 1: $\quad$ Comparison of the Provincial Distribution of Population in the 1\% Clustered Sample to that in $100 \%$ Census Tabulations, China, 1990

\begin{tabular}{|c|c|c|}
\hline Province & $\begin{array}{l}\text { Percent of Population } \\
\text { in } 100 \% \text { Tabulations }\end{array}$ & $\begin{array}{c}\text { Ratio of Sample } \\
\text { to Census }\end{array}$ \\
\hline Beijing & 0.96 & 1.03 \\
\hline Tianjin & 0.78 & 1.29 \\
\hline Hebei & 5.40 & 0.96 \\
\hline Shanxi & 2.54 & 1.03 \\
\hline Inner Mongolia & 1.90 & 1.02 \\
\hline Liaoning & 3.49 & 1.00 \\
\hline Jilin & 2.18 & 1.07 \\
\hline Heilongjiang & 3.12 & 1.00 \\
\hline Shanghai & 1.18 & 1.14 \\
\hline Jiangsu & 5.93 & 0.99 \\
\hline Zhejiang & 3.67 & 0.99 \\
\hline Anhui & 4.97 & 0.95 \\
\hline Fujian & 2.66 & 1.11 \\
\hline Jiangxi & 3.34 & 1.04 \\
\hline Shandong & 7.46 & 0.97 \\
\hline Henan & 7.57 & 0.96 \\
\hline Hubei & 4.77 & 1.03 \\
\hline Hunan & 5.37 & 1.02 \\
\hline Guangdong & 5.56 & 0.98 \\
\hline Guangxi & 3.74 & 1.03 \\
\hline Hainan & 0.58 & 1.09 \\
\hline Sichuan & 9.48 & 0.96 \\
\hline Guizhou & 2.87 & 0.95 \\
\hline Yunnan & 3.27 & 0.99 \\
\hline Tibet & 0.19 & 1.09 \\
\hline Shaanxi & 2.91 & 1.01 \\
\hline Gansu & 1.98 & 1.06 \\
\hline Qinghai & 0.39 & 1.27 \\
\hline Ningxia & 0.41 & 0.82 \\
\hline Xinjiang & 1.34 & 0.98 \\
\hline Total & $100.01 \%$ & 1.015 \\
\hline
\end{tabular}

Sources: Population Census Office of China (1993) and one percent clustered sample. 
Office 1992). For example, the 100 percent tabulation for Tibet shows that 76.3 percent of the rural population age 15 and above is illiterate. In the one percent sample, the corresponding figure is 77.4 percent. There is also a close correspondence with the rural age distribution, the distribution of rural women by their number of live births, and on other characteristics. The Tibetan sample may thus be useful for some purposes.

One other sample anomaly remains to be noted. The sample of dead persons includes four sample units that are in addition to the 8,514 sample units containing live persons. The four units, all in Guangzhou City, Guangdong Province, were apparently erroneously substituted for the death cases in four other Guangzhou sample units. These cases, 123 records in all, are included in the following comparisons. ${ }^{7}$

\section{Figure 1: $\quad$ County Coverage of One Percent Clustered Sample of the 1990 Chinese Census}

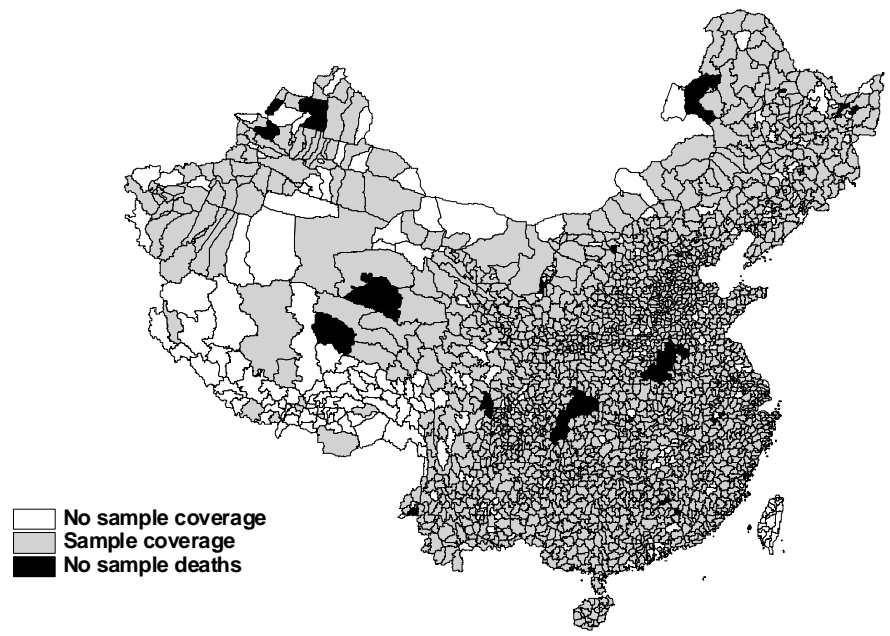

\footnotetext{
${ }^{7}$ The four dead-only units, all neighborhoods in the Liwan and Yuexiu Districts of Guangzhou Shi (GB 440103 and 440104 respectively), appear to be external to the original sample. This is suggested by the fact that both Liwan and Yuexiu are already fully represented by other neighborhoods containing live persons. Moreover, the Guangzhou Shi sample contains four neighborhoods with living persons but no corresponding dead persons, and three of these pertain to the same district (Liwan) that contains the dead-only units. This suggests an erroneous substitution of death records from non-sample neighborhoods. Thus, should the four dead-only units be excluded, it may be advisable to exclude the four living-only units of Guangzhou as well. The records from the dead-only units are included in the present assessment because their exclusion would have no appreciable affect on results at the national level. The 123 cases represent .0012 percent of the deaths in the total sample, and about 2.5 percent of the Guangdong Province sample. None of them pertain to persons age 0 .
} 


\section{National comparisons of sample and census}

A series of comparisons at the national level (Tables 2-3 and Figures 2-3) reveals a reasonable concordance between the sample and the underlying complete census data as derived from published tabulations (State Council Population Census Office 1993). When the total of persons in the sample is multiplied by the reciprocal of the sampling fraction (i.e., 100) and divided by the census total, the resultant ratio is 1.02. The one percent clustered sample thus overstates the census population by two percent (see Table 2). Births are similarly overstated, while for the death sample (after alternative adjustments to account for excluded counties, discussed in the next section) the ratio of adjusted sample to the $100 \%$ is .992 to .998 .

Having established a fair concordance between census and sample for total population, births, and deaths, we now consider the concordance of distributions of populations across various categories listed in Table 2. Most measures, such as percent male, percent rural, the sex ratio at birth, and deaths by semester, are within two percent of the census value. The distributions of population by occupation and by marital status are similarly close. There are two exceptions. The sample over-states the percent ever attending a university by 10 percent, perhaps as a consequence of the over-sample of the provincial level cities Shanghai and Tianjin that can be observed in Table 1. There is also an over-sampling of births in 1990 relative to 1989, for which we have no explanation.

Figure 2 presents a sample to census comparison of the sex-specific age distributions of those alive at the time of enumeration. The sample distribution of females by age is quite close to that for the census, varying within .5 percent at every age below 80. The male sample distribution is less regular. It contains an excess of males at ages 20-29, and a deficit of males age 60-75. Even so, these deviations are within one percent of the census value. The greater variability of males may be due to the greater concentration of males in sparse collective households and related institutional concentrations.

Figure 3, based on those who died in the 18-month period between January 1, 1989 and June 30, 1990, is constructed identically to Figure 2, but is based on age at death. The deviations of sample from census are more dramatic for the deceased. There is a notable dearth of dead males at ages 5-14-approximately 8 percent fewer than the corresponding census percentage. There is a similar dearth of females at ages 25-34. There are too many sample male death cases at ages 35-39, and too few sample female death cases at ages 45-49, approximately 10 percent fewer than expected. We have no explanation for these irregularities other than sampling variation. 
Table 2: Comparison of National Statistics Derived from the 1\% Clustered Sample to Corresponding Statistics Derived from Complete Enumeration Tabulations of the 1990 Chinese Census

\begin{tabular}{|c|c|c|}
\hline Item & $100 \%$ Census Value & Ratio of Sample to Census \\
\hline Total population & $1,130,510,638$ & 1.02 \\
\hline Births (enumerated) & $35,110,945$ & 1.01 \\
\hline Deaths & $10,328,899$ & .992 to $.998^{\mathrm{a}}$ \\
\hline Population \% male & 51.47 & 1.00 \\
\hline Population \% rural & 73.80 & 0.99 \\
\hline \multicolumn{3}{|l|}{ Population $\%$ in collective } \\
\hline households & 2.89 & 1.02 \\
\hline Population \% non-Han & 8.08 & 1.00 \\
\hline Sex ratio of births (enumerated) & 111.45 & 1.00 \\
\hline Sex ratio of births (mother reports) & 114.18 & 1.00 \\
\hline \multicolumn{3}{|l|}{ Births by semester ${ }^{b}$} \\
\hline Births 1989 first half \% & 32.25 & 0.98 \\
\hline Births 1989 second half \% & 37.88 & 0.98 \\
\hline Births 1990 first half \% & 29.87 & 1.04 \\
\hline Total & 100.00 & \\
\hline \multicolumn{3}{|l|}{ Deaths total by semester ${ }^{b}$} \\
\hline Deaths 1989 first half \% & 31.76 & 0.99 \\
\hline Deaths 1989 second half \% & 31.87 & 0.99 \\
\hline Deaths 1990 first half \% & 36.36 & 1.02 \\
\hline Total & 99.99 & \\
\hline \multicolumn{3}{|l|}{ Educational Level $^{\mathrm{b}}$} \\
\hline University \% & 0.62 & 1.10 \\
\hline Technical college \% & 0.97 & 1.04 \\
\hline Vocational high school \% & 1.74 & 0.97 \\
\hline Upper middle school \% & 7.30 & 1.01 \\
\hline Lower middle school \% & 26.50 & 1.00 \\
\hline Primary school \% & 42.27 & 1.00 \\
\hline Illiterate or semi-literate \% & 20.61 & 1.00 \\
\hline Total & 100.01 & \\
\hline
\end{tabular}


Table 2: Continued

\begin{tabular}{|c|c|c|}
\hline Item & $100 \%$ Census Value & Ratio of Sample to Census \\
\hline \multicolumn{3}{|l|}{ Occupation ${ }^{b}$} \\
\hline Professional and Technical \% & 5.32 & 1.02 \\
\hline Cadres $\%$ & 1.75 & 1.02 \\
\hline Administrative staff $\%$ & 1.74 & 0.98 \\
\hline Commercial workers \% & 3.01 & 1.01 \\
\hline Service workers \% & 2.40 & 1.02 \\
\hline Agricultural workers \% & 70.61 & 0.99 \\
\hline Production workers \% & 15.17 & 1.02 \\
\hline Total & 100.00 & \\
\hline \multicolumn{3}{|l|}{ Marital Status ${ }^{b}$} \\
\hline Unmarried \% & 25.13 & 1.00 \\
\hline Married \% & 68.18 & 1.00 \\
\hline Widowed \% & 6.10 & 1.00 \\
\hline Divorced \% & 0.59 & 1.00 \\
\hline Total & 100.00 & \\
\hline
\end{tabular}

Sources: Population Census Office of China (1993) and one percent clustered sample.

${ }^{a}$ Sample deaths are adjusted for lack of death coverage in certain counties under different assumptions; see text and note 9 for an explanation.

${ }^{b}$ Percentage distribution sums to 100 percent, with deviations due to rounding. 
Figure 2: $\quad$ Ratio of Sample to Census, Live Population, China, 1990.

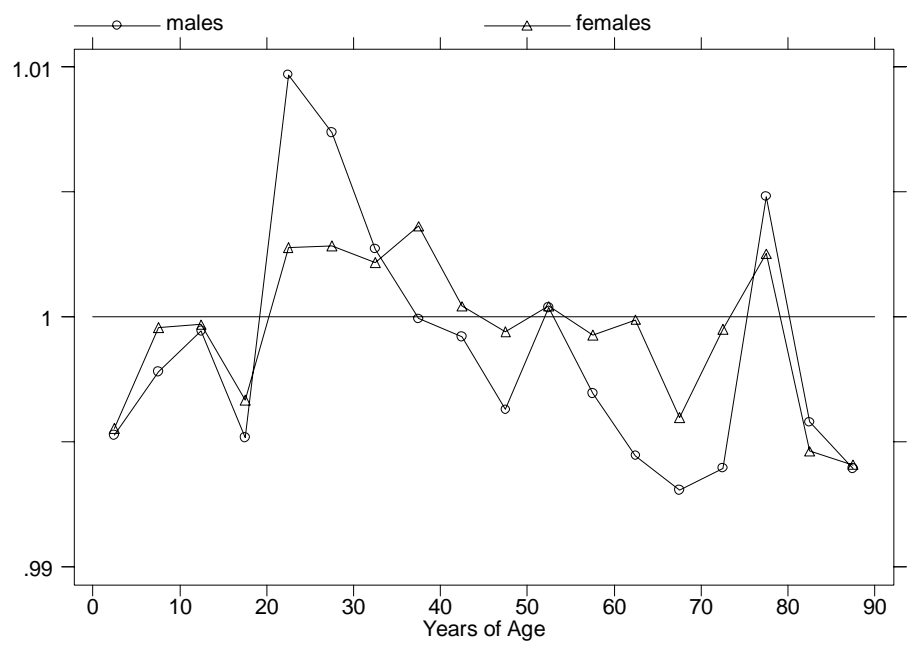

Sources: Population Census Office of China (1993) and one percent clustered sample.

Figure 3: $\quad$ Ratio of Sample to Census, Dead Population, China, 1990

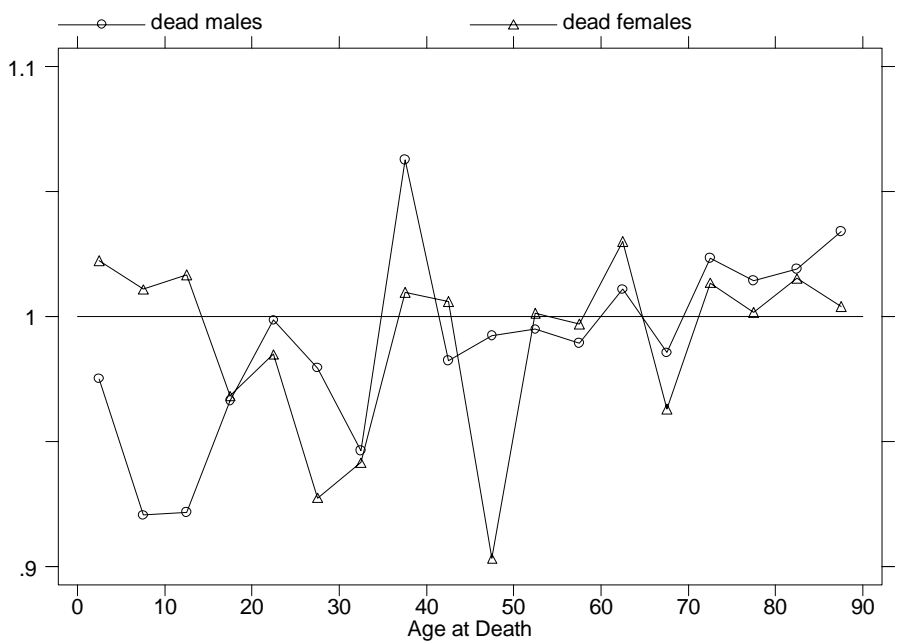

Sources: Population Census Office of China (1993) and one percent clustered sample. 
Because infant mortality is of particular interest, in Table 3 we further compare deaths at age 0 conditional on sex and semester of birth with the corresponding figures from published census tabulations. Official sources do not document the calculation of infant mortality rates with detail sufficient to sustain independent replication. For this reason our analysis is restricted to comparison of sample frequencies of infant death with those derived from the 100 percent enumeration tables (State Council Population Census Office 1993). The interior cells of Table 3 display ratios of sample infant deaths to complete enumeration infant deaths conditional on sex and semester of birth. The row and column margins contain ratios separately for sex and semester. Because of gaps in death coverage at all ages at the county level, which are discussed in the next section, the ratio of sample infant deaths to complete census infant deaths is less than one (.960), which suggests that the clustered sample undercounts infant deaths. However, upon adjusting for county coverage gaps in death reporting under the assumption that infant deaths were missed with probability identical to that for deaths to older individuals, the ratio of sample infant deaths to complete census infant deaths is found to be in the range of .991 to .999 . This result suggests that infant deaths are not specifically undersampled in the one percent clustered sample. The sex-semester specific ratios in Table 3 should thus be considered to be downwardly biased owing to the absence of adjustment for nonreporting of deaths in particular counties. Of greater concern is the apparent undersampling of male relative to female infant deaths in every semester, as well as the inconsistency over semesters in the relative undersampling. ${ }^{8}$ We have no explanation for this variability, but note that at a minimum it complicates the conclusions that can be drawn from individual level analyses of infant mortality.

\footnotetext{
${ }^{8}$ We employed Poisson and negative binomial models, and checked for over-dispersion, to reach these conclusions. The sex effect is significant at the .1 level. Of the semester contrasts, only that between the first and third semester is significant at the .05 level.
} 
Table 3: $\quad$ One Percent Cluster Sample Deaths at Age 0 (Multiplied by 100) Divided by Corresponding $100 \%$ Enumeration Deaths, Conditional on Sex and Semester of Death, China, 1990

\begin{tabular}{lccc}
\hline Semester & Male & Female & Total \\
\hline 1989: January-June & 0.911 & 0.946 & 0.928 \\
& $(120,406)$ & $(118,893)$ & $(239,299)$ \\
1989: July-December & 0.959 & 0.962 & 0.961 \\
& $(142,015)$ & $(145,593)$ & $(287,608)$ \\
1990: January-June & 0.943 & 1.02 & 0.981 \\
& $(177,418)$ & $(185,177)$ & $(362,595)$ \\
Total & 0.941 & 0.980 & 0.960 \\
& $(439,839)$ & $(449,663)$ & $(889,502)$ \\
\hline
\end{tabular}

Sources: Population Census Office of China (1993) and one percent clustered sample.

Note: Numbers in parentheses are death counts from 100 percent enumeration

${ }^{a}$ Sample values are unadjusted for lack of death coverage in certain counties; see text for discussion.

\section{County-level comparisons of sample and census}

For total population at the county level, if the sample data are unbiased, a regression of sample population counts on total enumeration population counts should return a coefficient that is approximately .01. For this calculation we found a slope of .0095 $(N=2,600)$. Fitting a cubic polynomial spline to the data revealed modest departures from linearity. If a handful of counties is excluded, the regression coefficient becomes .01. Thus, with respect to total population, the clustered one percent sample appears to be nearly unbiased at the county level.

We also compared total sample deaths to total census deaths at the county level. Here we detected a problem that required consideration prior to computation of a regression comparable to that for total population. Of the 2,600 county-level units in the clustered sample, 97 contain no death data. For a subset of these 97 counties, the absence of deaths is probably due to procedures followed at the local level, rather than to the inherent variability occasioned by probability sampling. In three contiguous prefectures in Henan (Shangqiu, Zhoukou, and Zhumadian), and two contiguous prefectures in Sichuan (Wanxian and Fuling), there are no mortality data. These five prefectures, containing 34,995,661 persons in 1990, account for 43 of the 97 county- 
level units for which there are no deaths. The county-level sample sizes in these prefectures range from a minimum of 1,600 to a maximum of 15,441 . Given the contiguity of the counties, and their correspondence to the areas of prefectural administrations, it is probable that the lack of mortality data in the 43 counties is due to some aspect of procedure and not sampling variability. In our judgment, these five prefectures should be excluded from any analysis of mortality.

The remaining 54 zero-death county-level units are geographically scattered, although many pertain to urban units in Heilongjiang and Anhui. They are far less populous on average than the 43 described above, together containing only 8,166,649 persons. It is at least theoretically possible that some or all of the sampled villages in these 54 county-level units recorded no deaths in the 18 months prior to the census. We addressed this question statistically, using total population as well as total death counts available in 1990 county census volumes. The structure of the inferential problem is to determine whether zero sampled deaths in each of the 54 counties is plausible or implausible, given a known death count and total population, and a sample population total, for each county. In our explorations, we concluded that zero sample deaths were implausible in all but nine of the counties. Other analysts might well use different methods and reach slightly different conclusions. For this reason, we present lower and upper bounds on the number of excluded counties. Specifically, at a minimum the 43 zero-death counties in five prefectures previously discussed should be excluded for the purposes of mortality analysis. At a maximum 97 zero-death counties should be excluded.

When zero-death counties are excluded, the complete-census death counts need to be reduced correspondingly, in order to make valid comparisons of sample-estimated deaths to complete-census deaths at the national level. The ratio of sample-to-census deaths in Table 2 provides this upper and lower bound for comparison. The lower bound is based on excluding 43 zero-death counties; the upper bound is based on excluding 97 zero-death counties. ${ }^{9}$ The 97 zero-death counties are portrayed in the map (Figure 1) with black shading; in the complete census, these counties contributed 3.79 percent of deaths. The 97 zero-death counties are listed in Appendix 1. ${ }^{10}$

If death sampling is unbiased at the county level, then a regression of sampled deaths at the county level on complete census deaths at the county level should have a slope that is approximately 0.01. Omitting the 43 counties in five zero-death prefectures, we find a slope of $.0096(\mathrm{~N}=2,276)$; omitting all 97 zero-death counties, we

\footnotetext{
${ }^{9}$ The first sample to census ratio of deaths in Table 2 excludes only deaths from the 43 zero-death counties of the five prefectures, while the latter excludes deaths from all 97 zero-death counties. Counties in the five prefectures account for $3.177 \%$ of census deaths, while all 97 counties account for $3.794 \%$ of census deaths.

${ }^{10}$ The 43 counties in the five zero-death prefectures in Henan and Sichuan are distinguished in Appendix 1 by GB code (4123xx, 4127xx, 4128xx, and 5122xx, 5123xx respectively).
} 
find a slope of $.0095(\mathrm{~N}=2,222) .{ }^{11}$ Thus, it appears, apart from the zero-death problem at the county level, that the one percent clustered sample is approximately unbiased for total deaths at the county level.

\section{Discussion}

The one percent clustered sample appears to be a true one percent sample of the 1990 census. It reproduces the geographic distribution of population and major population components quite well. Although the clustering of the sample reduces precision, it permits contextual analyses based on multilevel methods of statistical analysis.

There are anomalies. The sample for Tibet lacks urban units and appears to use a different sampling procedure. The national distribution of deaths by age for males is irregular, and male infant mortality is somewhat under-sampled relative to the census. These deficiencies must be assessed for their relevance to specific analytic purposes. For example, there is mounting evidence (e.g., Ministry of Health 1999) that the 1990 census underreported infant mortality by a margin far wider than the gap between sample and census infant mortality. Against this kind of uncertainty, the sample can be useful. The results of the sample/enumeration comparisons we have presented suggest that the one percent clustered sample will be serviceable for many purposes.

\section{Acknowledgements}

We gratefully acknowledge the valuable advice of Griffith Feeney and G. William Skinner, the research assistance of Yingying Zhou, and the support of the Henry Luce Foundation.

\footnotetext{
${ }^{11}$ The base $\mathrm{N}$ for this regression is limited to 2,319 county-level units because we lack $100 \%$ death data on 281 units, mainly urban districts.
} 


\section{References}

Fan, C. Cindy and Youqin Huang. 1998. "Waves of Rural Brides: Female Marriage Migration in China." Annals of the Association of American Geographers 88(2): 227-251.

Huang, Youqin. 2001. "Gender, Hukou, and the Occupational Attainment of Female Migrants in China (1985-1990)." Environment and Planning A, 33:257-279.

Li Shuzhuo and Zhu Chuzhu. 2000. Research and Community Practice on Gender Difference in Child Survival in China. Beijing: China Population Publishing House.

Ministry of Health, Peoples Republic of China. 1999. Zhongguo weisheng tongji tiyao 1999 (Chinese Health Statistical Digest 1999). Beijing: Health Press.

State Council Population Census Office, and Department of Population Statistics, State Statistical Bureau, People's Republic of China. 1993. Tabulation on the 1990 Population Census of the People's Republic of China. Beijing: China Statistical Publishing House. Four volumes.

State Statistical Bureau. 1994. "Data Structure of the 1990 Population Census of China." [Unpublished codebook.]

Tibet Autonomous Region Population Census Office. 1992. Tabulation on the 1990 Population Census of Tibet Autonomous Region. Lhasa: Tibet People's Publishing House. 


\section{Appendix 1:}

Zero Death Counties Selected for Exclusion from Mortality Analysis in the One Percent Clustered Sample, China, 1990

\begin{tabular}{|c|c|c|}
\hline GB Code & Province & Name \\
\hline 150103 & Inner Mongolia & Huhehaote: Huimin qu \\
\hline 150122 & Inner Mongolia & Tuoketuo xian \\
\hline 150402 & Inner Mongolia & Chifeng: Hongshan qu \\
\hline 210802 & Liaoning & Yingkou: Zhanqian qu \\
\hline 210803 & Liaoning & Yingkou: Xishi qu \\
\hline 210811 & Liaoning & Yingkou: Laobian qu \\
\hline 230402 & Heilongjiang & Hegang: Xiangyang qu \\
\hline 230403 & Heilongjiang & Hegang: Gongnong qu \\
\hline 230702 & Heilongjiang & Yichun: Yichun qu \\
\hline 230705 & Heilongjiang & Yichun: Xilin qu \\
\hline 230811 & Heilongjiang & Jiamusi: Jiaoqu \\
\hline 230826 & Heilongjiang & Huachuan xian \\
\hline 230834 & Heilongjiang & Youyi xian \\
\hline 230881 & Heilongjiang & Tongjiang shi \\
\hline 232603 & Heilongjiang & Wudalianchi shi \\
\hline 320703 & Jiangsu & Lianyungang: Lianyun qu \\
\hline 320704 & Jiangsu & Lianyungang: Yuntai qu \\
\hline 320705 & Jiangsu & Lianyungang: Xinpu qu \\
\hline 330921 & Zhejiang & Daishan xian \\
\hline 340302 & Anhui & Bengbu: Dong qu \\
\hline 340304 & Anhui & Bengbu: Xi qu \\
\hline 340404 & Anhui & Huainan: Xiejiaji qu \\
\hline 340503 & Anhui & Ma`anshan: Huashan qu \\
\hline 340702 & Anhui & Tongling: Tonggongshan qu \\
\hline 340803 & Anhui & Anqing: Daguan qu \\
\hline 341002 & Anhui & Huangshan shi CC: Tunxi qu \\
\hline 341003 & Anhui & Huangshan: Huangshan qu \\
\hline
\end{tabular}




\section{Appendix 1: $\quad$ Continued}

\begin{tabular}{|c|c|c|}
\hline GB Code & Province & Name \\
\hline 341004 & Anhui & Huangshan: Huizhou qu \\
\hline 341023 & Anhui & Yi xian \\
\hline 342101 & Anhui & Fuyang shi \\
\hline 342530 & Anhui & Jingde xian \\
\hline 350203 & Fujian & Xiamen: Siming qu \\
\hline 360302 & Jiangxi & Pingxiang: Chengguan qu \\
\hline 360311 & Jiangxi & Pingxiang: Shangli qu \\
\hline 362124 & Jiangxi & Dayu xian \\
\hline 362129 & Jiangxi & Dingnan xian \\
\hline 410411 & Henan & Pingdingshan: Jiaoqu \\
\hline 412321 & Henan & Yucheng xian \\
\hline 412322 & Henan & Shangqiu xian \\
\hline 412323 & Henan & Minquan xian \\
\hline 412324 & Henan & Ningling xian \\
\hline 412325 & Henan & Sui xian \\
\hline 412326 & Henan & Xiayi xian \\
\hline 412327 & Henan & Zhecheng xian \\
\hline 412328 & Henan & Yongcheng xian \\
\hline 412701 & Henan & Zhoukou shi \\
\hline 412721 & Henan & Fugou xian \\
\hline 412722 & Henan & Xihua xian \\
\hline 412723 & Henan & Shangshui xian \\
\hline 412724 & Henan & Taikang xian \\
\hline 412725 & Henan & Luyi xian \\
\hline 412726 & Henan & Dancheng xian \\
\hline 412727 & Henan & Huaiyang xian \\
\hline 412728 & Henan & Shenqiu xian \\
\hline 412729 & Henan & Xiangcheng xian \\
\hline 412801 & Henan & Zhumadian shi \\
\hline 412821 & Henan & Queshan xian \\
\hline
\end{tabular}




\section{Appendix 1: $\quad$ Continued}

\begin{tabular}{|c|c|c|}
\hline GB Code & Province & Name \\
\hline 412822 & Henan & Biyang xian \\
\hline 412823 & Henan & Suiping xian \\
\hline 412824 & Henan & Xiping xian \\
\hline 412825 & Henan & Shangcai xian \\
\hline 412826 & Henan & Ru`nan xian \\
\hline 412827 & Henan & Pingyu xian \\
\hline 412828 & Henan & Xincai xian \\
\hline 412829 & Henan & Zhengyang xian \\
\hline 450502 & Guangxi & Beihai: Haicheng qu \\
\hline 512201 & Sichuan & Wanxian shi \\
\hline 512221 & Sichuan & Wan xian \\
\hline 512222 & Sichuan & Kai xian \\
\hline 512223 & Sichuan & Zhong xian \\
\hline 512224 & Sichuan & Liangping xian \\
\hline 512225 & Sichuan & Yunyang xian \\
\hline 512226 & Sichuan & Fengjie xian \\
\hline 512227 & Sichuan & Wushan xian \\
\hline 512228 & Sichuan & Wuxi xian \\
\hline 512229 & Sichuan & Chengkou xian \\
\hline 512301 & Sichuan & Fuling shi \\
\hline 512322 & Sichuan & Dianjiang xian \\
\hline 512323 & Sichuan & Nanchuan xian \\
\hline 512324 & Sichuan & Fengdu xian \\
\hline 512326 & Sichuan & Wulong xian \\
\hline 513227 & Sichuan & Xiaojin xian \\
\hline 533121 & Yunnan & Luxi xian \\
\hline 610303 & Shaanxi & Baoji: Jintai qu \\
\hline 620105 & Gansu & Lanzhou: Anning qu \\
\hline 640121 & Ningxia & Yongning xian \\
\hline 654225 & Xinjiang & Yumin xian \\
\hline 654226 & Xinjiang & Hebukesai’er Mengguzu zizhixian \\
\hline
\end{tabular}

